Acta Crystallographica Section C

Crystal Structure

Communications

ISSN 0108-2701

Editor: George Ferguson

\title{
Cyclic and acyclic products from the reactions between methyl 3-oxobutanoate and arylhydrazines
}

\author{
James L. Wardell, Janet M. S. Skakle, John N. Low and Christopher Glidewell
}

Copyright ( International Union of Crystallography

Author(s) of this paper may load this reprint on their own web site or institutional repository provided that this cover page is retained.

Republication of this article or its storage in electronic databases other than as specified above is not permitted without prior permission in writing from the IUCr.

For further information see http://journals.iucr.org/services/authorrights.html 
Acta Crystallographica Section C

Crystal Structure

Communications

ISSN 0108-2701

\section{Cyclic and acyclic products from the reactions between methyl 3-oxo- butanoate and arylhydrazines}

\author{
James L. Wardell, ${ }^{a}$ Janet M. S. Skakle, ${ }^{\mathrm{b}}$ John N. Low ${ }^{\mathrm{b}}$ and \\ Christopher Glidewell ${ }^{\text {* }}$
}

anstituto de Química, Departamento de Química Inorgânica, Universidade Federal do Rio de Janeiro, 21945-970 Rio de Janeiro, RJ, Brazil, 'b Department of Chemistry, University of Aberdeen, Meston Walk, Old Aberdeen AB24 3UE, Scotland, and

${ }^{\mathbf{c}}$ School of Chemistry, University of St Andrews, Fife KY16 9ST, Scotland

Correspondence e-mail:cg@st-andrews.ac.uk

Received 14 June 2007

Accepted 15 June 2007

Online 14 July 2007

The molecules of methyl 3-(2-nitrophenylhydrazono)butanoate, $\mathrm{C}_{11} \mathrm{H}_{13} \mathrm{~N}_{3} \mathrm{O}_{4}$, (I), and methyl 3-(2,4-dinitrophenylhydrazono)butanoate, $\mathrm{C}_{11} \mathrm{H}_{12} \mathrm{~N}_{4} \mathrm{O}_{6}$, (II), both prepared from methyl 3-oxobutanoate and the corresponding nitrophenylhydrazine, exhibit polarized molecular electronic structures; in each of (I) and (II), the molecules are linked into chains by a single $\mathrm{C}-\mathrm{H} \cdots \mathrm{O}$ hydrogen bond. The molecules of 5-hydroxy3-methyl-1-phenyl- $1 \mathrm{H}$-pyrazole, $\mathrm{C}_{10} \mathrm{H}_{10} \mathrm{~N}_{2} \mathrm{O}$, (III), prepared by the reaction of methyl 3-oxobutanoate and phenylhydrazine, are linked into chains by a single $\mathrm{O}-\mathrm{H} \cdots \mathrm{N}$ hydrogen bond. The reaction between methyl 3-oxobutanoate and 3-nitrophenylhydrazine yields 5-hydroxy-3-methyl-1-(3nitrophenyl)-1 $H$-pyrazole, (IV), which when crystallized from acetone yields 4-isopropylidene-3-methyl-1-(3-nitrophenyl)$1 H$-pyrazol-5(4H)-one, $\mathrm{C}_{13} \mathrm{H}_{13} \mathrm{~N}_{3} \mathrm{O}_{3}$, (V).

\section{Comment}

We have for a number of years been interested in the structures of hydrazones (for examples, see Glidewell et al., 2003, 2004, 2006; Peralta et al., 2007; Wardell et al., 2005). As part of this wider study, we have now investigated the reactions of methyl 3-oxobutanoate (methyl acetoacetate) with a range of simple arylhydrazines. The reaction products include the acyclic 3-arylhydrazinobutanoate esters (I) and (II), the cyclized 1-aryl-5-hydroxypyrazoles (III) and (IV), and the condensation products such as (V), initially obtained during attempts to crystallize the pyrazole derivatives from ketonic solvents. We report here the structures of compounds (I)-(III) and $(\mathrm{V})$, and we integrate the various structural types into a single mechanistic scheme. The structure of (III) reported here represents a second polymorph of this compound; a monoclinic polymorph crystallizes with $Z^{\prime}=2$ in the space group $P 2{ }_{1} /$ c (Bechtel et al., 1973a; Chmutova et al., 2001).
Compounds (I)-(III) (Figs. 1-3) were readily obtained from the reactions between methyl 3-oxobutanoate and the appropriate arylhydrazines, viz. 2-nitrophenylhydrazine for (I), 2,4-dinitrophenylhydrazine for (II) and phenylhydrazine for (III). The analogous reaction using 3-nitrophenylhydrazine gave the product (IV), but the crystals initially obtained from methanol solution were of very poor quality and were twinned. The diffraction data obtained from these crystals were correspondingly poor, and we have been unable to reduce $R$ significantly below 0.11 ; thus, we do not report the structure of (IV) in detail here. Nonetheless, the atom connectivity revealed by these very poor data unambiguously corresponds to that of compound (IV), directly analogous to compound (III). Attempted recrystallization of compound (IV) from acetone solution yielded instead the condensation product (V) (Fig. 4), evidently a product of the reaction between (IV) itself and the acetone solvent.<smiles>[Y4]/C(CC(=O)OC)=N\Nc1ccccc1[N+](=O)[O-]</smiles><smiles>COC(=O)C/C(C)=N/Nc1ccc([N+](=O)[O-])cc1[N+](=O)[O-]</smiles>

(II)<smiles>Cc1cc(O)n(-c2ccccc2)n1</smiles>

(III)<smiles>Cc1cc(O)n(-c2cccc([N+](=O)[O-])c2)n1</smiles>

(IV)<smiles></smiles><smiles>CC1=NN(c2cccc([N+](=O)[O-])c2)C(=O)C1=C(C)C</smiles><smiles>Cc1cc(O)n(-c2ccccc2)c1O</smiles>

(VI)

The bond lengths in the aryl rings of (I) and (II) show significant variation (Table 1 ). In particular, the $\mathrm{C} 3-\mathrm{C} 4$ and C5-C6 bonds are substantially shorter than the other ring bonds; in addition, the $\mathrm{C} 2-\mathrm{N} 12$ and $\mathrm{C} 4-\mathrm{N} 14$ bonds are long for their type, while the nitro $\mathrm{N}-\mathrm{O}$ bonds are all long (Allen et al., 1987). The observations indicate that the polarized 


\section{organic compounds}

quinonoid forms (I $a$ ), and (II $a$ ) and (II $b$ ), respectively, are significant contributors to the overall electronic structures of (I) and (II). This behaviour is typical of that observed in 2-nitro- and 4-nitroanilines, but not in 3-nitroanilines (Cannon et al., 2001; Garden et al., 2001, 2002; Glidewell et al., 2001; Zakaria et al., 2001), and it indicates a reduction in the basicity and nucleophilicity of atom N1 in such 2- and 4-substituted species as compared with both the 3-nitro derivatives and the un-nitrated analogues. The aryl rings in (I) and (II) are almost coplanar with the chain-extended fragment between atoms $\mathrm{C} 1$ and $\mathrm{C} 13$ (Figs. 1 and 2), and the nitro groups are nearly

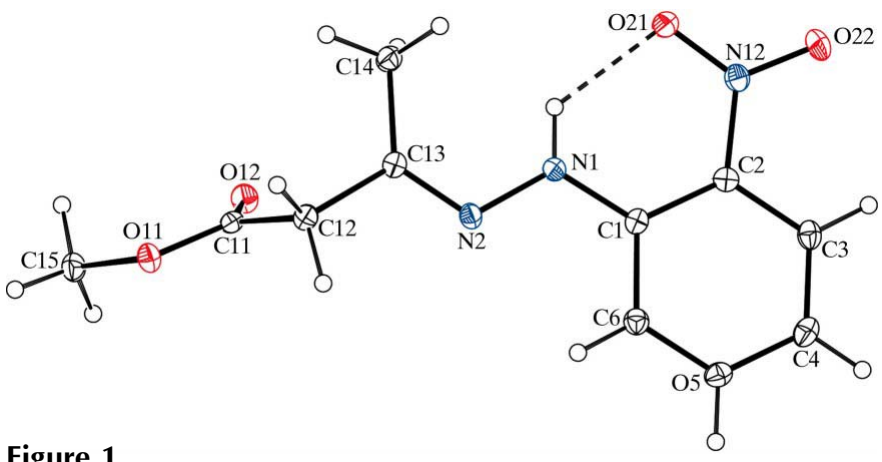

Figure 1

A molecule of (I), showing the atom-labelling scheme and the intramolecular $\mathrm{N}-\mathrm{H} \cdots \mathrm{O}$ hydrogen bond (dashed line). Displacement ellipsoids are drawn at the $30 \%$ probability level.

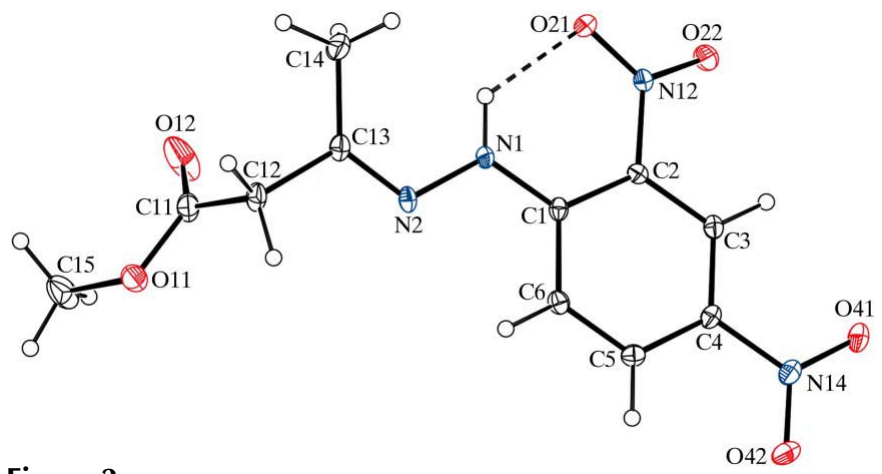

Figure 2

A molecule of (II), showing the atom-labelling scheme and the intramolecular $\mathrm{N}-\mathrm{H} \cdots \mathrm{O}$ hydrogen bond (dashed line). Displacement ellipsoids are drawn at the $30 \%$ probability level.

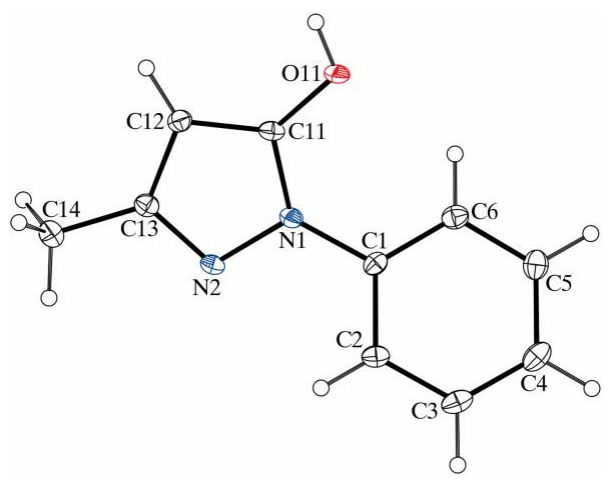

Figure 3

A molecule of (III), showing the atom-labelling scheme. Displacement ellipsoids are drawn at the $30 \%$ probability level. coplanar with the rings, as shown by the relevant torsion angles (Table 1). These nearly planar conformations may be influenced by the intramolecular $\mathrm{N}-\mathrm{H} \cdots \mathrm{O}$ interactions (Table 2). The ester fragments between atoms $\mathrm{C} 12$ and $\mathrm{C} 15$ are also nearly planar, but in each compound there is a substantial bend in the side chain at the $\mathrm{C} 12-\mathrm{C} 13$ bond.<smiles>COC(=O)C/C(C)=N/N=C1\C=CC=CC1=[N+]([O-])[O-]</smiles><smiles>COC(=O)CC(C)=NN=C1C=CC([N+](=O)[O-])=CC1=[N+]([O-])[O-]</smiles><smiles>COC(=O)CC(C)=NN=C1C=CC(=[N+]([O-])[O-])C=C1[N+](=O)[O-]</smiles>

The heterocyclic rings in (III) and (V) exhibit very different bond lengths (Table 2), consistent with significant $\pi$-delocalization in (III) and complete bond fixation in (V). The exocyclic $\mathrm{C}-\mathrm{O}$ bond lengths, in particular, are consistent with the location of the hydroxyl $\mathrm{H}$ atom in (III) as deduced from difference maps. The inter-ring dihedral angle is $22.0(2)^{\circ}$ in (III) and $6.2(2)^{\circ}$ in $(\mathrm{V})$, where the nitro group makes a dihedral angle of only $4.9(2)^{\circ}$ with the aryl ring.

The formation of the various products arising from the reactions of methyl acetoacetate with aryl hydrazines can readily be envisaged in terms of an initial condensation to form the acyclic $(E)$-hydrazone of type $(A)$, exemplified here

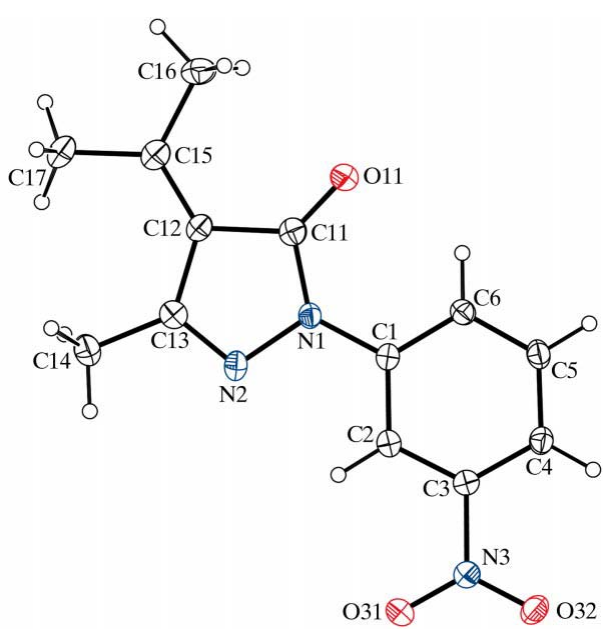

Figure 4

A molecule of $(\mathrm{V})$, showing the atom-labelling scheme. Displacement ellipsoids are drawn at the $30 \%$ probability level. 


\section{organic compounds}

by compounds (I) and (II). Provided that hydrazine atom N1 is sufficiently nucleophilic then the intermediate $(B)$ can readily cyclize, with loss of methanol, to form $(C)$, whose tautomer $(D)$ is exemplified by (III). Intermediate $(B)$ is simply the $Z$ isomer of $(A)$ and its formation most plausibly involves the tautomer $\left(A^{\prime}\right)$, in which effectively free rotation about the $\mathrm{N} 2-\mathrm{C} 13$ bond is possible. Condensation of $(C)$ with carbonyl compounds yields the exo-methylene derivatives $(E)$, exemplified here by compound (V). We have noted above the evidence for the significance of polarized electronic forms in (I) and (II), and an important consequence of such charge separation is the reduction in nucleophilicity of atom N1 when the aryl group contains 2-nitro and/or 4-nitro substituents. The structural evidence from (I) and (II) is thus consistent with the failure of these two compounds to undergo cyclization under the reaction conditions that produce (III) and (IV). When atom $\mathrm{N} 1$ is more nucleophilic, as in the presence of either an unsubstituted phenyl ring or a 3-nitrophenyl ring, cyclization to form $(C)$ and $(D)$ is thus feasible.<smiles>C=CCOC(=O)/C=C(\C)NN[Al]N/N=C(\C)CC(=O)OC</smiles>

(A)<smiles>CC1=NN([Al])C(=O)C1</smiles>

(D)<smiles>C=CC(=O)C/C(C)=N\N[Al]</smiles>

(B)<smiles>CC(=O)C1=NN([Al])C(=O)C1=C(C)C</smiles>

(E)
While there are no direction-specific interactions of any kind in the structure of (V), the molecules in (I), (II) and (III) are all linked into chains; in each of (I) and (II), the chain is built from a single $\mathrm{C}-\mathrm{H} \cdots \mathrm{O}$ hydrogen bond, and that in (III) by a single $\mathrm{O}-\mathrm{H} \cdots \mathrm{N}$ hydrogen bond (Table 3 ). In (I), methylene atom $\mathrm{C} 12$ in the molecule at $(x, y, z)$ acts as a hydrogen-bond donor to carbonyl atom O12 in the molecule at $(x,-1+y, z)$, so generating by translation a $C(4)$ (Bernstein et al., 1995) chain running parallel to the [010] direction (Fig. 5). In (II), the hydrogen-bond donor and acceptor are both different from those utilized in (I). In (II), aryl atom C6 in the molecule at $(x, y, z)$ acts as a hydrogen-bond donor to nitro atom $\mathrm{O} 42$ in the molecule at $\left(-\frac{1}{2}+x, \frac{3}{2}-y, 1-z\right)$, so forming a $C(6)$ chain running parallel to [100] and generated by the $2_{1}$ screw axis along $\left(x, \frac{3}{4}, \frac{1}{2}\right)$ (Fig. 6 ). In (III), hydroxy atom $\mathrm{O} 11$ in the molecule at $(x, y, z)$ acts as a hydrogen-bond donor to pyrazole atom $\mathrm{N} 2$ in the molecule at $\left(\frac{3}{2}-x, y,-\frac{1}{2}+z\right)$, so forming a $C(5)$ chain running parallel to the [001] direction and generated by the $c$-glide plane at $x=\frac{3}{4}$ (Fig. 7). There are no direction-specific interactions between the chains in compounds (I) and (III), but those in (II) are weakly linked by a dipolar carbonyl-nitro interaction. Carbonyl atom O12 in

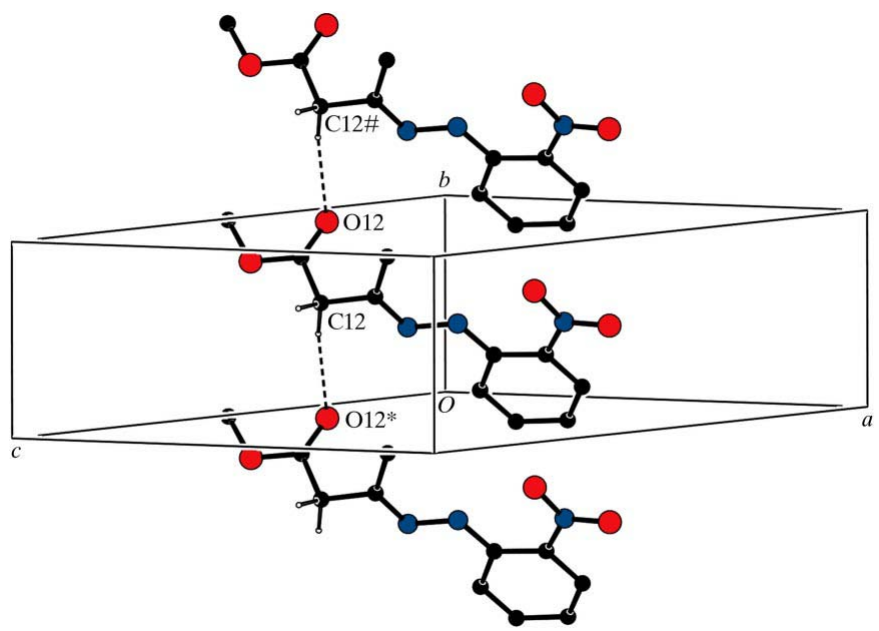

Figure 5

Part of the crystal structure of (I), showing the formation of a hydrogenbonded chain along [010]. For the sake of clarity, $\mathrm{H}$ atoms bonded to the $\mathrm{C}$ or $\mathrm{N}$ atoms not involved in the motif shown have been omitted. Atoms marked with an asterisk (*) or a hash (\#) are at the symmetry positions $(x,-1+y, z)$ and $(x, 1+y, z)$, respectively.

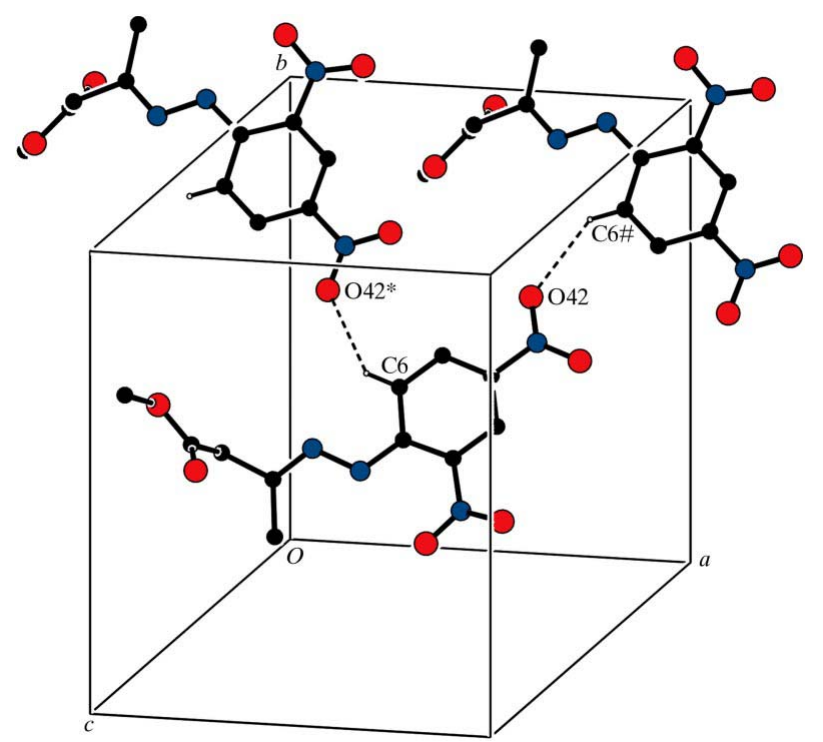

Figure 6

Part of the crystal structure of (II), showing the formation of a hydrogenbonded chain along [100]. For the sake of clarity, $\mathrm{H}$ atoms bonded to the $\mathrm{C}$ or $\mathrm{N}$ atoms not involved in the motif shown have been omitted. Atoms marked with an asterisk $(*)$ or a hash $(\#)$ are at the symmetry positions $\left(-\frac{1}{2}+x, \frac{3}{2}-y, 1-z\right)$ and $\left(\frac{1}{2}+x, \frac{3}{2}-y, 1-z\right)$, respectively. 


\section{organic compounds}

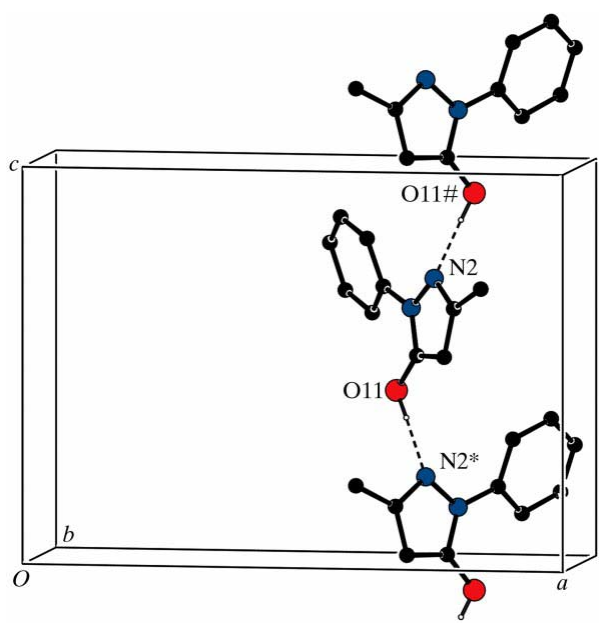

Figure 7

Part of the crystal structure of (III), showing the formation of a hydrogenbonded chain along [001]. For the sake of clarity, $\mathrm{H}$ atoms bonded to the $\mathrm{C}$ or $\mathrm{N}$ atoms not involved in the motif shown have been omitted. Atoms marked with an asterisk $(*)$ or a hash (\#) are at the symmetry positions $\left(\frac{3}{2}-x, y,-\frac{1}{2}+z\right)$ and $\left(\frac{3}{2}-x, y, \frac{1}{2}+z\right)$, respectively.

the molecule at $(x, y, z)$, which forms part of the hydrogenbonded chain along $\left(x, \frac{3}{4}, \frac{1}{2}\right)$, makes a nearly linear contact with nitro atom $\mathrm{N} 12$ in the molecule at $\left(-\frac{1}{2}+x, y, \frac{3}{2}-z\right)$, which lies in the hydrogen-bonded chain along $\left(x, \frac{3}{4}, 1\right)\left[\mathrm{O} \cdots \mathrm{N}^{\mathrm{i}}=\right.$ $2.885(2) \AA$ and $\mathrm{C}-\mathrm{O} \cdots \mathrm{N}^{\mathrm{i}}=173.7(2)^{\circ}$; symmetry code: (i) $\left.-\frac{1}{2}+x, y, \frac{3}{2}-z\right]$, and the effect of this contact is to link the [100] chains weakly into a sheet parallel to (010).

The monoclinic polymorph of (III) (Bechtel et al., 1973a; Chmutova et al., 2001) is, in fact, a 1:1 cocrystal of the two tautomeric forms 5-hydroxy-3-methyl-1-phenylpyrazole and 3-methyl-1-phenyl-2H-pyrazolin-5-one, (III $a$ ), and the molecules are linked by alternating $\mathrm{O}-\mathrm{H} \cdots \mathrm{O}$ and $\mathrm{N}-\mathrm{H} \cdots \mathrm{N}$ hydrogen bonds into $C_{2}^{2}(10)$ chains. By contrast, the sulfur analogue of (II) exists in the crystalline state solely as the thione tautomer (Chmutova et al., 2001). Isomeric with (III) is 3-hydroxy-5-methyl-1-phenylpyrazole, (VI), which exists in the crystalline state as a single tautomer; the compound crystallizes with $Z^{\prime}=2$ in the space group Pbca and the molecules are linked by two independent $\mathrm{O}-\mathrm{H} \cdots \mathrm{N}$ hydrogen bonds into $R_{2}^{2}(8)$ dimers, which do not exhibit even approximate symmetry (Bechtel et al., 1973b).

\section{Experimental}

For the synthesis of (I), a solution of methyl acetoacetate $(1 \mathrm{mmol})$ and 2-nitrophenylhydrazine $(1 \mathrm{mmol})$ in methanol $(10 \mathrm{ml})$ was heated under reflux for $30 \mathrm{~min}$; the solution was cooled to ambient temperature and then evaporated to dryness. The product, (I), was recrystallized from ethanol. IR $\left(\mathrm{KBr}, \mathrm{cm}^{-1}\right)$ : 3330, 1731, 1613, 1575. Heating a solution of (I) in ethanol for $1 \mathrm{~h}$ at reflux temperature led to no cyclization or other change. Compound (II) was similarly prepared from methyl acetoacetate and 2,4-dinitrophenylhydrazine, but the heating time was $90 \mathrm{~min}$; compound (II) was recrystallized from ethanol. IR $\left(\mathrm{KBr}, \mathrm{cm}^{-1}\right)$ : 3327, 1740, 1620, 1594. Compound (III) was prepared from the reaction of methyl acetoacetate and phenylhydrazine, exactly as for (I). The product was recrystallized

from ethanol [m.p. 398-400 K; literature m.p. $400 \mathrm{~K}$ (Singh, 2005)]. IR $\left(\mathrm{KBr}, \mathrm{cm}^{-1}\right)$ : 3130-2700, 1569, 1534. For the synthesis of (IV), a solution of methyl acetoacetate $(1 \mathrm{mmol})$ and 3-nitrophenylhydrazine hydrochloride $(1 \mathrm{mmol})$ in methanol $(20 \mathrm{ml})$ was heated under reflux for $30 \mathrm{~min}$; the solution was cooled to ambient temperature and then evaporated to dryness. The residue was recrystallized from ethanol, but this material was not suitable for single-crystal X-ray diffraction. IR $\left(\mathrm{KBr}, \mathrm{cm}^{-1}\right)$ : 3120, 3100-2300, $1591,1556,1530$. Further recrystallization of (IV) from acetone gave (V). IR (KBr, $\left.\mathrm{cm}^{-1}\right)$ : 1688, 1614, 1529.

\section{Compound (I)}

Crystal data

$\mathrm{C}_{11} \mathrm{H}_{13} \mathrm{~N}_{3} \mathrm{O}_{4}$

$M_{r}=251.24$

Monoclinic, $P 2_{1} / n$

$a=12.1494(4) \AA$

$b=5.1355(2) \AA$

$c=18.6969$ (6) $\AA$

$\beta=102.079(2)^{\circ}$

\section{Data collection}

Bruker-Nonius KappaCCD diffractometer

Absorption correction: multi-scan (SADABS; Sheldrick, 2003)

$T_{\min }=0.975, T_{\max }=0.995$

\section{Refinement}

$R\left[F^{2}>2 \sigma\left(F^{2}\right)\right]=0.045$

$w R\left(F^{2}\right)=0.117$

$S=1.05$

2617 reflections

\section{Compound (II)}

Crystal data

$\mathrm{C}_{11} \mathrm{H}_{12} \mathrm{~N}_{4} \mathrm{O}_{6}$

$M_{r}=296.25$

Orthorhombic, $\mathrm{Pbca}$

$a=10.6100$ (3) ^

$b=12.1878(4) \AA$

$c=20.522(2) \AA$

\section{Data collection}

Bruker-Nonius KappaCCD

diffractometer

Absorption correction: multi-scan

(SADABS; Sheldrick, 2003)

$T_{\min }=0.961, T_{\max }=0.983$

Refinement

$R\left[F^{2}>2 \sigma\left(F^{2}\right)\right]=0.044$

$w R\left(F^{2}\right)=0.116$

$S=1.05$

3033 reflections

\section{Compound (III)}

Crystal data

$\mathrm{C}_{10} \mathrm{H}_{10} \mathrm{~N}_{2} \mathrm{O}$

$M_{r}=174.20$

Orthorhombic, $P c a 2_{1}$

$a=15.0138(9) \AA$

$b=5.2952(3) \AA$

$c=10.9469(6) \AA$
$V=1140.73(7) \AA^{3}$

$Z=4$

Mo $K \alpha$ radiation

$\mu=0.11 \mathrm{~mm}^{-1}$

$T=120(2) \mathrm{K}$

$0.28 \times 0.22 \times 0.04 \mathrm{~mm}$

13943 measured reflections 2617 independent reflections 1931 reflections with $I>2 \sigma(I)$ $R_{\text {int }}=0.053$

166 parameters

$\mathrm{H}$-atom parameters constrained

$\Delta \rho_{\max }=0.26 \mathrm{e}^{-3}$

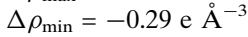

$V=2653.7(3) \AA^{3}$

$Z=8$

Mo $K \alpha$ radiation

$\mu=0.12 \mathrm{~mm}^{-1}$

$T=120(2) \mathrm{K}$

$0.43 \times 0.35 \times 0.14 \mathrm{~mm}$

20035 measured reflections 3033 independent reflections 2289 reflections with $I>2 \sigma(I)$ $R_{\text {int }}=0.061$

192 parameters $\mathrm{H}$-atom parameters constrained $\Delta \rho_{\max }=0.27{\mathrm{e} \AA^{-3}}^{-3}$ $\Delta \rho_{\min }=-0.25 \mathrm{e}^{-3}$
$V=870.29(9) \AA^{3}$

$Z=4$

Mo $K \alpha$ radiation

$\mu=0.09 \mathrm{~mm}^{-1}$

$T=120(2) \mathrm{K}$

$0.22 \times 0.09 \times 0.02 \mathrm{~mm}$ 


\section{organic compounds}

\section{Data collection}

Bruker-Nonius KappaCCD diffractometer

Absorption correction: multi-scan (SADABS; Sheldrick, 2003)

$T_{\min }=0.974, T_{\max }=0.998$

\section{Refinement}

$R\left[F^{2}>2 \sigma\left(F^{2}\right)\right]=0.039$

$w R\left(F^{2}\right)=0.093$

$S=1.12$

1051 reflections

120 parameters

\section{Compound (V)}

Crystal data

$\mathrm{C}_{13} \mathrm{H}_{13} \mathrm{~N}_{3} \mathrm{O}_{3}$

$M_{r}=259.26$

Monoclinic, $P 2_{1} / c$

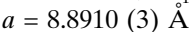

$b=10.1699$ (6) $\AA$

$c=13.4731$ (7) $\AA$

$\beta=100.415$ (3)

\section{Data collection}

Bruker-Nonius KappaCCD

diffractometer

Absorption correction: multi-scan

(SADABS; Sheldrick, 2003)

$T_{\min }=0.958, T_{\max }=0.985$

Refinement

$R\left[F^{2}>2 \sigma\left(F^{2}\right)\right]=0.060$

$w R\left(F^{2}\right)=0.165$

$S=1.04$

2752 reflections

$V=1198.17(10) \AA^{3}$

$Z=4$

Mo $K \alpha$ radiation

$\mu=0.11 \mathrm{~mm}^{-1}$

$T=120(2) \mathrm{K}$

$0.36 \times 0.24 \times 0.14 \mathrm{~mm}$

15923 measured reflections 2752 independent reflections 1840 reflections with $I>2 \sigma(I)$ $R_{\text {int }}=0.057$

175 parameters

$\mathrm{H}$-atom parameters constrained

$\Delta \rho_{\max }=0.53 \mathrm{e}^{-3}$

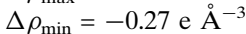

Table 1

Selected bond distances and torsion angles $\left(\AA,^{\circ}\right)$ for (I) and (II).

\begin{tabular}{lcr}
\hline & $(\mathrm{I})$ & $(\mathrm{II})$ \\
\hline $\mathrm{C} 1-\mathrm{C} 2$ & $1.411(2)$ & $1.420(2)$ \\
$\mathrm{C} 2-\mathrm{C} 3$ & $1.403(2)$ & $1.388(2)$ \\
$\mathrm{C} 3-\mathrm{C} 4$ & $1.368(3)$ & $1.374(2)$ \\
$\mathrm{C} 4-\mathrm{C} 5$ & $1.401(2)$ & $1.402(2)$ \\
$\mathrm{C} 5-\mathrm{C} 6$ & $1.368(2)$ & $1.373(2)$ \\
$\mathrm{C} 6-\mathrm{C} 1$ & $1.414(2)$ & $1.413(2)$ \\
$\mathrm{C} 1-\mathrm{N} 1$ & $1.366(2)$ & $1.3612(19)$ \\
$\mathrm{C} 2-\mathrm{N} 12$ & $1.438(2)$ & $1.4517(19)$ \\
$\mathrm{N} 12-\mathrm{O} 21$ & $1.2482(18)$ & $1.2394(16)$ \\
$\mathrm{N} 12-\mathrm{O} 22$ & $1.2363(17)$ & $1.2290(16)$ \\
$\mathrm{C} 4-\mathrm{N} 14$ & - & $1.4503(19)$ \\
$\mathrm{N} 14-\mathrm{O} 41$ & - & $1.2352(17)$ \\
$\mathrm{N} 14-\mathrm{O} 42$ & - & $1.2378(17)$ \\
$\mathrm{C} 2-\mathrm{C} 1-\mathrm{N} 1-\mathrm{N} 2$ & & $173.08(13)$ \\
$\mathrm{C} 1-\mathrm{N} 1-\mathrm{N} 2-\mathrm{C} 13$ & $-178.57(14)$ & $-179.46(14)$ \\
$\mathrm{N} 1-\mathrm{N} 2-\mathrm{C} 13-\mathrm{C} 12$ & $-178.70(15)$ & $178.09(13)$ \\
$\mathrm{N} 2-\mathrm{C} 13-\mathrm{C} 12-\mathrm{C} 11$ & $-178.15(13)$ & $101.57(17)$ \\
$\mathrm{C} 13-\mathrm{C} 12-\mathrm{C} 11-\mathrm{O} 11$ & $-113.65(17)$ & $176.12(14)$ \\
$\mathrm{C} 12-\mathrm{C} 11-\mathrm{O} 11-\mathrm{C} 15$ & $-171.48(13)$ & $0.9(2)$ \\
$\mathrm{C} 1-\mathrm{C} 2-\mathrm{N} 12-\mathrm{O} 21$ & $-178.88(13)$ & \\
$\mathrm{C} 3-\mathrm{C} 4-\mathrm{N} 14-\mathrm{O} 41$ & $-3.8(2)$ & \\
\hline
\end{tabular}

For (I), (II) and (V), respectively, the space groups $P 2_{1} / n, P b c a$ and $P 2_{1} / c$ were uniquely assigned from the systematic absences. For (III), the systematic absences permitted $P c a 2_{1}$ and $P b c m(=P c a m)$ as possible space groups; $P c a 2_{1}$ was selected and confirmed by the
Table 2

Selected bond lengths ( $)$ for (III) and (V).

\begin{tabular}{lll}
\hline & $(\mathrm{III})$ & $(\mathrm{V})$ \\
\hline $\mathrm{N} 1-\mathrm{N} 2$ & $1.387(3)$ & $1.433(3)$ \\
$\mathrm{N} 2-\mathrm{C} 13$ & $1.333(3)$ & $1.288(3)$ \\
$\mathrm{C} 13-\mathrm{C} 12$ & $1.394(3)$ & $1.452(3)$ \\
$\mathrm{C} 12-\mathrm{C} 11$ & $1.378(3)$ & $1.500(3)$ \\
$\mathrm{C} 11-\mathrm{N} 1$ & $1.364(3)$ & $1.371(3)$ \\
$\mathrm{C} 11-\mathrm{O} 11$ & $1.329(3)$ & $1.205(3)$ \\
$\mathrm{C} 12-\mathrm{C} 15$ & - & $1.361(3)$ \\
\hline
\end{tabular}

Table 3

Hydrogen bonds and short intramolecular contacts $\left(\AA,^{\circ}\right)$ for (I)-(III) and $(\mathrm{V})$.

\begin{tabular}{lllll}
\hline$D-\mathrm{H} \cdots A$ & $D-\mathrm{H}$ & $\mathrm{H} \cdots A$ & $D \cdots A$ & $D-\mathrm{H} \cdots A$ \\
\hline (I) & & & & \\
$\mathrm{N} 1-\mathrm{H} 1 \cdots \mathrm{O} 21$ & 0.88 & 1.97 & $2.6077(19)$ & 128 \\
$\mathrm{C} 12-\mathrm{H} 12 A \cdots \mathrm{O} 12^{\mathrm{i}}$ & 0.99 & 2.42 & $3.3894(19)$ & 166 \\
& & & & \\
(II) & & & & 128 \\
$\mathrm{~N} 1-\mathrm{H} 1 \cdots \mathrm{O} 21$ & 0.93 & 1.95 & $2.6258(17)$ & 139 \\
$\mathrm{C} 6-\mathrm{H} 6 \cdots \mathrm{O} 42^{\mathrm{ii}}$ & 0.95 & 2.51 & $3.293(2)$ & 178 \\
(III) & & & & 118 \\
$\mathrm{O} 11-\mathrm{H} 11 \cdots \mathrm{N} 2^{\mathrm{iii}}$ & 0.84 & 1.79 & $2.633(3)$ & \\
$\mathrm{C} 6-\mathrm{H} 6 \cdots \mathrm{O} 1$ & 0.95 & 2.31 & $2.881(3)$ & \\
(V) & & & & \\
C6-H6 $\cdots \mathrm{O} 1$ & 0.95 & 2.24 & $2.871(3)$ & 123 \\
\hline
\end{tabular}

Symmetry codes: (i) $x, y-1, z$; (ii) $x-\frac{1}{2},-y+\frac{3}{2},-z+1$; (iii) $-x+\frac{3}{2}, y, z-\frac{1}{2}$.

successful structure analysis. All $\mathrm{H}$ atoms were located in difference maps and then treated as riding atoms. $\mathrm{H}$ atoms bonded to $\mathrm{C}$ atoms were placed in geometrically idealized positions and allowed to ride, with $\mathrm{C}-\mathrm{H}$ distances of 0.95 (aromatic and pyrazole), $0.98\left(\mathrm{CH}_{3}\right)$ or $0.99 \AA\left(\mathrm{CH}_{2}\right)$, and with $U_{\text {iso }}(\mathrm{H})=k U_{\text {eq }}(\mathrm{C})$, where $k=1.5$ for the methyl groups and $k=1.2$ otherwise. $\mathrm{H}$ atoms bonded to $\mathrm{N}$ or $\mathrm{O}$ atoms were allowed to ride at the distances deduced from difference maps $[\mathrm{N}-\mathrm{H}=0.88 \AA$ in $(\mathrm{I})$ or $0.93 \AA$ in $(\mathrm{II})$, and $\mathrm{O}-\mathrm{H}=0.84 \AA$, with $U_{\text {iso }}(\mathrm{H})=1.2 U_{\text {eq }}(\mathrm{N})$ or $\left.1.5 U_{\text {eq }}(\mathrm{O})\right]$. In the absence of significant resonant scattering it was not possible to establish the correct orientation of the structure of (III) with respect to the polar-axis direction; accordingly, the Friedel-equivalent reflections were merged prior to the final refinements. Compound (IV) has unit-cell dimensions $a=25.648$ (4) $\AA$, $b=3.8259$ (6) $\AA$, $c=24.790$ (5) $\AA$ and $\beta=$ $118.739(14)^{\circ}$ in the space group $P 2 / c$; the compound was crystallized from ethanol as a hemihydrochloride salt, $2 \mathrm{C}_{10} \mathrm{H}_{9.5} \mathrm{~N}_{3} \mathrm{O}_{3}{ }^{0.5+} \cdot \mathrm{Cl}^{-}$and the crystals were twinned, as well as exhibiting very poor overall quality.

For all compounds, data collection: COLLECT (Hooft, 1999); cell refinement: DENZO (Otwinowski \& Minor, 1997) and COLLECT; data reduction: $D E N Z O$ and $C O L L E C T$; program(s) used to solve structure: OSCAIL (McArdle, 2003) and SHELXS97 (Sheldrick, 1997); program(s) used to refine structure: OSCAIL and SHELXL97 (Sheldrick, 1997); molecular graphics: PLATON (Spek, 2003); software used to prepare material for publication: SHELXL97 and PRPKAPPA (Ferguson, 1999).

X-ray data were collected at the EPSRC National Crystallography Service, University of Southampton, UK. The authors thank the staff for all their help and advice. JLW thanks CNPq and FAPERJ for financial support. 


\section{organic compounds}

Supplementary data for this paper are available from the IUCr electronic archives (Reference: SK3141). Services for accessing these data are described at the back of the journal.

\section{References}

Allen, F. H., Kennard, O., Watson, D. G., Brammer, L., Orpen, A. G. \& Taylor, R. (1987). J. Chem. Soc. Perkin Trans. 2, pp. S1-19.

Bechtel, F., Gaultier, J. \& Hauw, C. (1973a). Cryst. Struct. Commun. 3, 469-472. Bechtel, F., Gaultier, J. \& Hauw, C. (1973b). Cryst. Struct. Commun. 3, 473 476.

Bernstein, J., Davis, R. E., Shimoni, L. \& Chang, N.-L. (1995). Angew. Chem. Int. Ed. Engl. 34, 1555-1573.

Cannon, D., Glidewell, C., Low, J. N., Quesada, A. \& Wardell, J. L. (2001). Acta Cryst. C57, 216-221.

Chmutova, G. A., Kataeva, O. N., Ahlbrecht, H., Kurbangalieva, A. R., Movchan, A. I., Lenstra, A. T. H., Geise, H. J. \& Litvinov, I. A. (2001). J. Mol. Struct. 570, 215-223.

Ferguson, G. (1999). PRPKAPPA. University of Guelph, Canada.

Garden, S. J., Fontes, S. P., Wardell, J. L., Skakle, J. M. S., Low, J. N. \& Glidewell, C. (2002). Acta Cryst. B58, 701-709.

Garden, S. J., Glidewell, C., Low, J. N., McWilliam, S. A., Pinto, A. C., Skakle, J. M. S., Torres, J. C. \& Wardell, J. L. (2001). Acta Cryst. C57, 1212-1214.
Glidewell, C., Cannon, D., Quesada, A., Low, J. N., McWilliam, S. A., Skakle, J. M. S. \& Wardell, J. L. (2001). Acta Cryst. C57, 455-458.

Glidewell, C., Low, J. N., Skakle, J. M. S. \& Wardell, J. L. (2003). Acta Cryst. C59, o98-o101.

Glidewell, C., Low, J. N., Skakle, J. M. S. \& Wardell, J. L. (2004). Acta Cryst. C60, o686-0689.

Glidewell, C., Low, J. N., Skakle, J. M. S. \& Wardell, J. L. (2006). Acta Cryst. B62, 666-675.

Hooft, R. W. W. (1999). COLLECT. Nonius BV, Delft, The Netherlands.

McArdle, P. (2003). OSCAIL for Windows. Version 10. Crystallography Centre, Chemistry Department, NUI Galway, Ireland.

Otwinowski, Z. \& Minor, W. (1997). Methods in Enzymology, Vol. 276, Macromolecular Crystallography, Part A, edited by C. W. Carter Jr \& R. M. Sweet, pp. 307-326. New York: Academic Press.

Peralta, M. A., Souza, M. N. V. de, Wardell, S. M. S. V., Wardell, J. L., Low, J. N. \& Glidewell, C. (2007). Acta Cryst. C63, o68-o72.

Sheldrick, G. M. (1997). SHELXS97 and SHELXL97. University of Göttingen, Germany.

Sheldrick, G. M. (2003). SADABS. Version 2.10. University of Göttingen, Germany.

Singh, S. P. (2005). Synth. Commun. 25, 611-619.

Spek, A. L. (2003). J. Appl. Cryst. 36, 7-13.

Wardell, S. M. S. V., Souza, M. V. N. de, Wardell, J. L., Low, J. N. \& Glidewell, C. (2005). Acta Cryst. C61, o683-0689.

Zakaria, C. M., Low, J. N., Skakle, J. M. S., McWilliam, S. A., Wardell, J. L. \& Glidewell, C. (2001). Acta Cryst. C57, 1207-1208. 